\title{
The Enemy of Environmentalism: Struggles with Divergent Convergence
}

\author{
Robert M.W. Brown
}

Concomitant with Ithiel de Sola Pool's estimation of convergence and divergence (de Sola Pool 1983), environmentalism was beginning to articulate its own struggle with the perception of convergence as synonymous with technological enclosure while attempting to articulate a notion of divergence capable of sustaining holistic alternatives. Convergence is not necessarily foreign to the ecological sciences. In meteorology, convergence describes the confluences or channeling of air streams. In oceanography, convergence occurs when two or more water masses or currents meet. Or, according to the evolutionary sciences, convergence describes the process by which unrelated organisms express parallel adaptations when pressured by similar environmental conditions ("Convergence" 1998). Nor is divergence something entirely new: often used by the ecological sciences to express antithetical phenomena, within meteorology divergence is the loss of air flow, in hydrology divergence is an upwelling or movement away from a central flow, or as conceptualized by the evolutionary sciences, divergence represents the genetic segregation and differentiation that define derivative taxa ("Divergence" 1998). Moreover, even technological convergence and divergence are consistent with developments in scientific and humanistic ecology via cybernetics, thermodynamics, and first order systems theory.

The difficulty for many North American environmentalists was that the threats posed by the biomagnification of DDT, Love Canal, and the partial meltdown of the Three Mile Island nuclear reactor were inseparable from an interpretation of cultural convergence definitive of globalization, technological rationality, scientific 
objectivity, and the instrumentalization that was degrading ecosystem functions. A distinction was drawn between 'natural' convergence stylized by the pre-war life sciences and 'unnatural' or post-war forms of reified divergence as alienated from environmental health and material security. ${ }^{1}$ Or rephrased, for an environmental movement that was defined by maintaining a clear set of normative binary extremes oriented by a distinction between Nature and the unnatural, it was difficult to see convergence and divergence as constituting a reticulated process. While biological convergence/divergence was near sacred, technological convergence/divergence was used to define the conditions of enmity. Antithetical difference could not be suspended to allow for a codependent tension that negotiates both the limitations and potentiality that are posited by the work of convergence and the dehiscence that is categorical of divergent acts.

In effect, and here drawing directly from Henry Jenkins, in an attempt to critique the perceived dogma of technocratic civilization, environmentalism repeated the tendency it was organizing against by transcribing the "old authorities" and building up "the institutions being challenged by a more participatory culture" $(2006,198)$. Environmentalism had failed to realize that convergence is divergence while committing the movement to a logic of enmity vis-à-vis a paralyzing attempt to pit friend against foe.

In what follows I will trace the logic of enmity through three movements. First, I will establish the rift between shallow and deep ecology as defined by Arne Naess and elaborated by Neil Evernden to describe the historical foundation of enmity. Second, I will present the attempt to redevelop convergence through the post-environmentalism of American think tank the Breakthrough Institute, to question whether convergence is possible when the underlying logic of the enemy is preserved. And third, I will forward the description of Canadian radical environmentalism as ecological terrorism to display one possible way in which divergence is being used as a forced constitution of enmity. In each case I suggest that the logic of enmity eliminates the potential of convergence/divergence as participatory culture in an attempt to orient and control actors through the maintenance of cultural warfare.

\section{Fragmented Ecologies}

It is of the utmost importance that Jenkins's interpretation of convergence and divergence begins with the rejection of the singular. Technological convergence will never fulfill the dream of the singular black box any more than culture will ever be universal. While there will be a proliferation of means, this does not foreshadow a proleptic end that will see the fulfillment of a totalized system.

1 Examples of the former would include Frederic E. Clements's development of the 'climax state' (1916). 
When such a totalized system is divined, it should evoke a deep skepticism that attempts to disclose what the logic of finality conceals. This should have been the case for the environmentalists of the 1970s and 1980s. As environmentalism postured to resist technological convergence as a totalized system that was subsuming marginalized ways of life, this criticism was often a screen for an ulterior mode of organic territoriality as questionable as its presumed antithesis.

Natural or biological convergence and unnatural or technological convergence are extensions of first and second nature. 'First nature,' the radical ideal, defines nature as a set of immutable laws, a heteronomy that when viewed as a total system is thought to maintain the ecological harmony and function of biological systems. 'Second nature' is the work of culture, the active practice or habit of development and construction. 'Second nature' superimposes an ancillary nature over the first as the social construction of the culture industry demands. Not surprisingly, the attempt to maintain this normative boundary or border directly supports the division between hard-line restorative approaches that would see environments returned to or preserved in their original or natural state, over and against adaptive measures like regulative and technological fixes capable of maintaining the status quo. Furthermore, not only were environmentalists maintaining a division between themselves and a social body largely constructed as environmentally destructive, but the move against technological convergence was also a strategic idealization used to systematically differentiate radical and reformist tendencies in an attempt to determine which faction(s) within environmentalism have the right to speak as the 'true' environmentalism.

Idealization begins with Arne Naess, the founder of deep ecology. By Naess's account, environmentalism could be divided between a powerful shallow ecology movement defined by the management and policing of resources for the health and welfare of affluent individuals in the developed world, over and against a marginal deep ecology movement motivated by "principles of diversity, complexity, autonomy, decentralization, symbiosis, egalitarianism and classlessness" (Naess 1995, 3). Or, as cultural ecologist Neil Evernden phrased it, deep ecology had defined a paradox within the identity of environmentalism itself. If shallow ecology was a variation on technological rationality that preserved natural resources to manage or control the processes of monetization, distribution, and consumption, then the attempt to "preserve nature" was little more than a licence to exploit nature (Evernden 1984a, 7). Environmentalism was balanced uneasily between the presupposed "integrity" of a radical environmental movement defined by the advocacy of nature's intrinsic worth against the "co-option" of nature in the hands of what Evernden described as 'resourceism,' or more simply, environmentalism (1984b, 5):

Publicly, it [environmentalism] has seemed profoundly reformist, even radical, and yet its methods have increasingly become those of the institutions it opposed. Many have wondered whether it is possible to adopt the tools 
and assumptions of industrial society and still remain significantly different. Hence the concern that there may be a paradox at the heart of modern environmentalism, a misfit between stated intentions and actual, or even potential, accomplishment. (1984b, 5)

The impetus behind Evernden's own articulation of the deep/shallow division was Rachel Carson's Silent Spring (1962) and her attempt to develop a grassroots base for nature advocacy. Legitimized by the damage to ecosystem function and health evidenced by the pervasive application of DDT, Carson created a generalized sense of concern that was founded on an exceedingly broad interpretation of what constituted environment (Evernden 1984a, 8). Opposed to an anthropocentric defence of human health and welfare, environment was introduced as an ambiguous yet inclusive concept that extended protection beyond both human and non-human forms of life to include the protection of biological systems in general. The importance of this shift was three-fold. First, environment became "endangered." Extending beyond the advocation and protection of lovemarks like charismatic megafauna or the sublime spaces of nature reserves, the evocation of an endangered environment intuited a systemic and persistent environmental threat that was inseparable from quotidian life. Second, the terms of political engagement shifted. Instead of defending environment with humanistic appeals, it was now possible to make a "smart" argument for safeguarding the biotic community as good in and of itself. Third, and most importantly, lowering barriers to involvement created a "new constituent." Environmentalism after Carson was no longer defined by highly specific sites or localized by special interests. Similar to the pervasiveness of DDT, support could now be drawn from virtually "every sector of a society uniformly threatened by environmental decay" (Evernden 1984a, 8).

Though Silent Spring may have set out the radical archetype - what Evernden termed the "nature advocate" - it was becoming resoundingly clear that shallow ecology was compromising the programme intuited by Carson and "true" environmentalism was giving way to a tragic reversal that would be the undoing of all environmentalism. The inclusive space opened by the conceptual expansion of environment had become the home for an expanding environmental movement dominated by the concerns of government, industry insiders, and experts practicing "sound environmental management" (Evernden 1984a, 8-9). "Ecological became a prefix for most public activity" - ecological managers, planners, technicians, programme coordinators, assessment specialists, and so on and so forth ad infinitum (Evernden 1984a, 9). Too easily, the "smart" argument was becoming the "rational" argument and in doing so, the protection of an ambiguous environment manifested by intrinsic value, affect, and attachment was reduced to a calculable variable to be negotiated by way of externalities, cost-benefit analysis, and the impact assessment that was definitive of technocratic logic. The shift toward the expanded notion of environment had clearly made it possible to attract a larger subset of individuals into the movement while also unifying these actors through a mutual 
cause or crisis that was larger than localized concerns. Yet this expansion was also abasing and diluting the idealization of value and meaning (Evernden 1984a, 9) as the constitution of the environmentalist permitted such a wide range of actors that both friend and foe where occupying a shared set of conceptual delineations. Environmentalism had become contradictory; defined not by the "nature advocate" but by the "dispassionate advocate" (Evernden 1984a, 9).

The latent evocations of divergence used to construct deep and shallow ecology cannot be stressed enough. Moving well beyond a political, social, or even epistemological designation, the negotiation of divergence was used to describe a cultural tension central to many within depth ecology. By Evernden's account, the antinomy between the nature advocate and the dispassionate advocate correlated directly to opposed manifestations of subjectivity and the constitution of existential territory. The dispassionate advocate resubstantiates the boundaries that popular intellectual history has used to situate the subject and instrumentalize the world by way of science and mathematics. Making a point that requires little repetition, by reconstituting the determinative fiction that was set out by the popularization of Cartesianism, the dispassionate advocate perpetuates a style of juxtaposition and binary extreme that is definitive of the distinction between subject and object. Representing what amounts to hackneyed interpretation of Max Weber's 'Entzauberung der Welt,' the world is demystified, despiritualized, or disenchanted, while subjectivity is raised to preternatural status.

For the nature advocate, the division between subject and object is an arbitrary expression of dominance. Although the expansion of environment freed of the Cartesian dualism was said to be ambiguous, for many ecologists the critique of objectivity was little more than a means to reintroduce a modified version of subjectivity that endowed environment with the techniques of the self. The most popular version of this tendency recapitulated a logic that had already been established by the deontological ethics of the early animal liberation movement by endowing environment with the rights and obligations that had been previously reserved for humanity. Depth ecology, however, intended something more radical by the reconstitution of the subject. As Evernden argued, when the environment is intuited as not only ambiguous and pervasive but also non-anthropocentric, it is the subject that becomes like an environment. The extensionist imperative doubles whereby the human encapsulates environment and environment encapsulates the human. In its first instance, this reversal entails an epistemological shift that Evernden describes as the "organic thought." Taking a metaphor from evolutionary biology, subjectivity is a mutualistic, symbiotic, or convergent relationship. Like the codependence between humans and domesticated flora and fauna or the relationship between the human body and the various microorganisms therein, Evernden suggests that what constitutes the subject extends well beyond the singular subject. In this regard, it can also be said that what is intersubjective is intercorporeal. The entwinement of subjects extends existence well beyond epidermal borders, and the practice of living through the world radically expands the existential territory of the 
subject. Paraphrasing one of Evernden's latently political metaphors, while a fish like the male stickleback is relatively small and insignificant, during breeding season the fish disregards its shortcoming and fiercely defends its territory as if environment were the fish, regardless of a predator's size and status on the food chain $(1995,44)$. Thinking the subject as an environment means first thinking the subject as inseparable from the territoriality that it defines as itself. Moreover, it is this transition that marks the divestment of the Cartesian logic, and the revelation of the "organic thought" as the embodied mind is reticulated through the zone of habitation. Making the transition from a conceptual epistemology toward a practical philosophy driven by affect, the development of territory manifests a field of concern. The subject as environment undergoes the deeper realization that integrates mere extension into a lived experience or emotional zone of attachment. The territorial field of self becomes the properly environmental field of care. Or, drawing on the emotionally charged language deployed by Evernden, the environment becomes a territory and the territory becomes the home. The occluded principle is that the territory is only recognized in practice when defined through and against the externalization of enmity - when a predatory faction is positioned at the ramparts of ecological civilization.

\section{Counter Convergence}

By the late 1990s it was becoming clear that the North American environmental movement was suffering from stagnation. The hope of Earth Days, hallmark political policies, and drafted climate protocols were beginning to reveal the limitations of resourceism. Moreover, as climate change issues were unresolved by existing actors, the support of the broader social body was giving way to skepticism, apathy, and a deep complacency. Unlike previous environmental concerns such as DDT or the acidification of rain, anthropogenic climate change as a diverse and dispersed event complicates the creation of a binding policy, technological fixes, and an unambiguous cost-benefit analysis. Yet it is also difficult to separate this general malaise from the resistance to change exhibited by the environmental movement over the past several decades. Viewed from even a marginal distance, it was clear that shallow ecology was failing to capture the public imagination while, at the same time, the money being raised by environmental non-governmental organizations (ENGOs) was having little influence on the creation of policy and legislation.

The internal stagnation of environmentalism met a threshold with Ted Nordhaus and Michael Shellenberger's newly founded non-profit Breakthrough Institute (BTI) and the publication of their highly divisive "The Death of Environmentalism: Global Warming Politics in a Post-Environmental World" (2004) and Break Through: Why We Can't Leave Saving the Planet to Environmentalists (2007). As Peter Teague summarized in his foreword to "The Death of Environmentalism," 
while the environmental movement was still captivated by the "epic victories" that established the environmental laws and policies of the 1960s and 1970s, after hundreds of millions of dollars have been spent on climate change issues, little has been achieved and environmentalism has failed to "engage Americans as the proud moral people they are, willing to sacrifice for the right cause" (Nordhaus and Shellenberger 2004, 4-5).

The BTI was unwilling to fault climate inaction on the media, politicians, or the fossil fuels lobby, and instead called for a post-environmental movement capable of questioning the foundational logic of environmentalism as such (Nordhaus and Shellenberger 2004, 5). For the BTI the stagnation or death of environmentalism was premeditated by the sectarian concept of environment evoked by depth ecology paired with the formalization of shallow ecology as a special interest group that divested its commitments as a social movement. Yet in both cases environmentalism was being over-determined by a naïve construction of Nature. ${ }^{2}$ Being sectarian, the discourse of Nature was silencing the production of creative or divergent narratives in favour of enmity. Or, as the normative foundation of special interests, Nature was prohibiting the creation of a convergence culture capable of realizing the organization and participation of diverse actors needed to combat climate change.

Once again criticism began with the interrogation of environmentalism's origin and the legacy left by Carson. As much as Silent Spring had expanded participation within the movement, the construction of environment as endangered had popularized an eco-tragic framework that would become a definitive model for public relations over the next half century (Nordhaus and Shellenberger 2009, 130). Reaching a climax when climate discourse was blended with millennial anxiety, the eco-tragic narrative involves a systemic evocation of pastoral life, followed by the development of fear through the threat of ecological collapse, and ultimately, the restoration of draconian values aimed at creating an ecological society. The result was a long ecological tragedy from Cartesianism to technocentrism and the judgment that looms at the precipice of eco-apocalypse. The difficulty with the ecotragic is two-fold. Firstly, there is a great deal of debate over the effectiveness of eco-tragic narratives. While it is widely believed that Carson's apocalyptic portrayal of DDT shocked the American public into action, recent studies are suggesting that the abysmal magnitude of climate change is being met with either repression and denial or a paradigm of manageable or rationalized fear that orients and legitimizes existing modes of political, economic, and technological control. ${ }^{3}$ Secondly, under the conditions of climate change and the proliferation of exceedingly violent weather, it is difficult to suspend the latent violence of the natural even if the un-

2 The BTI adopts the capitalization of 'Nature' in what appears to be an attempt to displace the inherent naturalization of the concept and express a latent essentialism.

3 See, for instance, Ulrich Beck's Risk Society: Towards a New Modernity (1992) and Naomi Klein's The Shock. Doctrine: The Rise of Disaster Capitalism (2007). 
derlying cause is anthropogenic. In both cases the harmony of Nature, though ideal, does not represent the real or total conception of the natural world or even the heterogeneous figures that are used to situate the expression of nature in the popular imagination:

The categories of Nature, the environment, natural and unnatural have long since been deconstructed. And yet they retain their mythic and debilitating hold over most environmentalists. Environmentalists imagine that they are objectively representing scientific facts about what is happening to Nature. But to imagine Nature as essentially harmonious is to ignore the obvious and overwhelming evidence of Nature's disharmony. (Nordhaus and Shellenberger 2009, 133; emphasis in the original)

Instead, Nordhaus and Shellenberger invoke something much closer to the violence of the Hobbesian state of nature as a war of all against all preserved by $\mathrm{Na}$ ture in the present, complete with the addition of the BTI's own brand of colonial naturalization and essentialism:

But long before there were humans, volcanoes erupted, asteroids hit Earth, and great extinctions occurred. Fires burned through ancient forests, killing undergrowth and creating conditions for new life. And throughout the animal kingdom there was murder and gang rape [...] activities that hardly qualify as harmonious. Indigenous peoples, for their part, cleared forests, set massive fires, and over-hunted, massively altering their environments. And they engaged in agriculture, war, cannibalism, and torture. $(2009,132)$

Though verging on the hyperbolic, the categorization of Nature, free from antinomy, fails. The constellation set out by the eco-tragic framework does little to motivate or inspire progressive action and ultimately undermines the sense of freedom and autonomy that binds the idealized American social contract. The reality, say Nordhaus and Shellenberger, is that this narrative is little more than a critique of human agency: "Rather than dissolving the distinction between humans and $\mathrm{Na}$ ture, environmentalists reverse the hierarchy, arguing that humans are still separate from but subordinate to Nature" (2009, 134-135; emphasis in the original).

The BTI's solution to essentialist Nature was a self-proclaimed progressive or pragmatic post-environmentalism founded on participatory action and the creation of a right of centre convergence culture. "Our strategy was to create something inspiring," write Nordhaus and Shellenberger. "Something that would remind people of the American dream: that we are a can-do people capable of achieving great things when we put our minds to it." In short, a "patriotic story [...] [that] uses big solutions to frame the problem - not the other way around" (Nordhaus and Shellenberger 2004, 26). To this end, the pragmatic approach was positioned as a "metaphysic of becoming" that adopted narratives that substantiated the affirmative, creative, and participatory culture of everyday America to meet emerging post-material needs such as belonging and fulfillment (Nordhaus and Shellenberger 
2009, 219-220). In this case, Malcolm Gladwell and Robert Putnam's appraisal of Reverend Rick Warren and the Saddleback Church provides the model for the BTI's culture of convergence. To sustain any long-term commitment both environmental organizations and evangelical megachurches are faced with a similar contradiction: to develop large memberships they maintain general or low entry barriers while nurturing specific identities that are distinct from their larger culture (Gladwell 2005). For environmentalism, this has resulted in a fragmented membership and watered down political stances as organizations struggle to maintain funding and attract a diverse membership without producing a contradictory or exclusionary mandate. Warren, however, successfully maintained a large membership while developing a participatory community. To lower the barriers of entry Warren crafted a quotidian faith. "[...] Warren started preaching, often in a Hawaiian shirt, about what really matters to people. His speeches were funny and free of fire and brimstone. He preached about things like how to deal with emotionally difficult people, how to be a good spouse, and how to simplify one's life" (Nordhaus and Shellenberger 2009, 199). Not only was Warren able to retain a staggeringly large membership, but he also successfully oriented his members as a heterogeneous community by building a religious network of small groups. Joining exclusive groups of six or seven individuals, members meet in each other's homes to worship and pray: "The small group was an extraordinary vehicle of commitment. It was personal and flexible. It cost nothing. It was convenient, and every worshipper was able to find a small group that precisely matched his or her interests" (Gladwell 2005). The network of small groups solves the problem of retention by creating an intimate and engaged community to represent and develop the divergent concerns of individuals within a much larger convergent community. Where increased anonymity and decreased financial and personal commitment are typical of large memberships, the dedication developed through small groups led to strong financial support capable of funding large outreach programmes to expand the distribution of Warren's brand (Gladwell). While a serious evangelical from a median-income family is likely to donate $\$ 6,000$ to his/her local church yearly, a serious environmentalist is likely to donate $\$ 100$ yearly (Nordhaus and Shellenberger 2009 , 203). Not only had the shallow environmentalism failed to articulate itself as a proper social movement, the lack of community development was also limiting the financial reach of organizations.

If for Evernden the struggle between convergence and divergence was resolved through the creation of territory and the affirmation of a true environmentalism, for the BTI clearing the field and constituting counter convergence and divergence solve the problems of environmentalism. Yet, in doing so, does the BTI itself not commit itself to the logic of enmity? Is the bravado of the American dream not simply a refrain that proclaims the second coming of Western empire and a renewed age of enmity? Can there be any participatory culture of convergence/divergence if this culture is founded on an act of primordial violence that attempts the complete privation of one system in the exultation of another? If 
environmentalism ceased to be a social movement through its repulsion of the social body and the creation of enmity, does the BTI not reproduce a similar logic with its attempt to efface environmentalism?

\section{Forced Divergence}

In 2009 Canadian awareness of climate change rose to an astounding 95\% (Pelham $2009)$. Of that, $61 \%$ of the population agreed that climate change was being caused by human activities (Pelham), while $74 \%$ of the population saw climate change as a threat (Pugliese and Ray 2009). Even if these statistics cannot be correlated with strong support of binding climate change action when prioritized against economic concerns, it was clear that Canadians were siding with the international scientific community. This did not, however, stop Conservative Prime Minister Stephen Harper from repudiating the Kyoto Accord while quickly mobilizing support and development for the Northern Gateway and the Keystone XL tar sands pipelines. In this regard, a slip of the tongue committed by Canada's former Minister of Environment, Peter Kent, attested to a hesitation that was felt by many Canadians. Fumbling the government's formal withdrawal from Kyoto that stated, "we are invoking our legal right to formally withdraw from Kyoto" (Environment Canada 2011), Kent announced, "we are evoking our legal right to withdraw from Canada" ("Canada" 2011). Where once Canadians had associated nationality with the optics of an environmentally progressive nation and international environmental leadership, this illusion had succumbed to a very different actuality where environmental protection was no longer synonymous with governmentality. Either the Government of Canada had withdrawn from its existing social contract with Canadian citizens, or the Government of Canada had withdrawn from the Canadian nation state.

The extent to which the Government of Canada was willing to defend oil interests became readily apparent after Harper's conservatives had secured a majority government in 2011 and successfully passed the intentionally vague 2012 federal omnibus budget. Among austerity cuts to social welfare programmes like health, welfare, native rights, and immigration, the Harper government made it astoundingly clear that any challenge to the development and distribution of the tar sands would not be tolerated by defunding a series of dissenting intergovernmental actors. This included gutting The Canadian Environmental Assessment Act to 'streamline' assessment that interfered with the economic development and wellbeing of the country, while defunding research programmes like the Centre for Offshore Oil, Gas and Energy Research which was one of the few agencies capable of offshore environmental assessments, the National Roundtable on Environment and Economy which was a site for open discussion between industry and environmental concerns, the Experimental Lakes Area and their ongoing research on the effects of tar sands pollution on freshwater ecosystems, and the Canadian 
Foundation for Climate and Atmospheric Science which resulted in the closure of the Polar Environment Atmospheric Research Laboratory and ended their studies on ozone depletion.

What was being described by most ENGOs as Harper's "war on science" was, however, just one aspect of a much larger strategy for the development of the tar sands. Having eliminated internal sources of opposition, the Government of Canada began an attempt to alter the branding of Canadian ENGOs to eliminate external sources of opposition. In January 2012 Joe Oliver, then Minister of Natural Resources, published an open letter defending the attempt to "diversify" Canada's energy market and "streamline the regulatory process in order to advance Canada's national economic interest" against environmental radicals being funded by foreign interest groups (Natural Resources Canada 2012). This was followed by the February 2013 Public Safety publication "Building Resilience against Terrorism" (Public Safety Canada 2013) which formally extended the definition of domestic terror to include radical environmentalists. As John Bennett, Director of Sierra Club Canada, noted:

We are one of the few segments of Canadian society that has continually stood up to the present Conservative government and been able to be effective at raising issues [...] As a result, they've decided that we're political opponents rather than a part of the democratic dialogue. So this is just the next stage in these attacks. (qtd. in Stoymenoff 2012)

The dilemma that Bennett faced was that any attempt to defend ENGOs against the extended definition of terror had the potential to be considered an admission of guilt simply by voicing resistance against government authority. What followed was a modest media push questioning whether environmentalism was the new face of domestic terror and if so, what measure should be taken. Regardless of whether the evocation of eco-terror was exceptionally vague, by August 2012 the conservative-leaning Sun News Network had funded a poll that concluded 1 in 2 Canadians now believed that the threat of domestic eco-terrorism was high or moderate. As David Akin wrote: “the Conservative government's verbal attacks on 'environmental and other radical groups' have sparked a fear, most prevalent among Conservative voters, of an eco-terrorist attack on Canada's energy infrastructure [...]." Or as pollster David Coletto furthered: "It is clear that the Harper government's framing on issues around energy infrastructure security and 'radical environmental groups' has been successful in dividing the population" (qtd. in Akin 2012).

Even if the outcome of this discourse remains to be seen, this much is clear: by mobilizing an extended definition of terrorism, the Government of Canada is in the process of criminalizing radical environmentalism by extension. ${ }^{4}$ Following the

4 During the publication of this paper the Government of Canada has launched Bill C-51, the AntiTerrorism Act, in response to two unrelated domestic 'lone-wolf' attacks that occurred in October 2014. Many critics believe that the ambiguity of the bill and the extended powers described therein 
American model as established by Steve Vanderheiden, the Government of Canada is conflating radical tactics that have periodically involved the destruction of private property with the formal definitions of terrorism that threatens human life (Vanderheiden 2008, 300). Making something of an ironic reversal, opposed to extending the rights and values of subjectivity to establish ecological principles to defend environmental concerns, the Government of Canada extends the status of subjectivity to materiality employed in the production of environmental denigration - in this instance oil lines, extraction infrastructure, and equipment. In doing so, the line between the destruction of private property and attacks on human life is blurred as illegal tactics like ecotage or monkey wrenching become the "moral equivalent of mass murder" (Vanderheiden 300). Moreover, by marginalizing relevant public research bodies, the Harper government had eliminated the ability for both research centres and the ENGOs reliant on their data to critique the policies and actions of the federal government. Such attempts at silencing environmentalists often result in renewed radicalization (Vanderheiden 301). Organizations and alliances that have previously divested the destruction of private property often fragment as they debate the relevance of extra-legal activism. The disenfranchised become further radicalized and the Government of Canada's use of wedge politics could succeed in creating the conditions for illegal forms of activism that can then be labeled as eco-terrorism, thus furthering the divide between the social body and the environmental movement. Yet, perhaps more importantly, the Government of Canada has effectively limited the ability of convergence by attempting to force militant divergence. While illegal tactics are often used to slow the denigration of environmentally sensitive areas, erode industry brands, portray environmental destruction as near criminal offences, and develop community support (Vanderheiden 306-308), it now seems that the divergent practices definitive of radical environmentalism can be easily translated into the propaganda of brutal criminality. Opposed to providing a radical alternative, the production of divergence is employed to erode environmentalism at large. The logic of enmity used to unite the radical movement holds the possibility to end the movement when divergence is turned against itself.

\section{Ecologism}

Despite claims that depth ecology went 'deeper' by calling into question the political, social, and cultural norms and values sanctioning ecological degradation, the movement resubstantiates the binary logic it sought to contend by preparing a discourse that is pursuing the production of collective subjectivity through the

violate the Canadian Charter of Rights and Freedoms by providing the legal means to survey, infiltrate, disrupt, detain, and incarcerate a growing network of First Nations, environmentalists, scientists, and academics engaged in anti-extractivism. 
constitution of an enemy. In an attempt to manifest a new convergence culture over and against the perceived failure of both deep and shallow ecology, the BTI defines environmentalism as foe and sets out the constitution of the friend. Or, where radical divergence was used as tactic to reframe corporate brands and develop community support, non-violent tactics are conceptualized as formal acts of terror. In each case, environmentalism is defined through the constitution of an enemy - so much so that it seems questionable whether the environmental movement has ever been more than a negative proof or a regulative principle that forged unity through a shared drive towards annihilation. If so, the claims to participatory action, diversity, pragmatism, and the protection of difference maintained by the idealization of ecological society are severely limited. Ecology becomes ecologism - a border war between self and other or between 'mere' environmentalism and 'true' environmentalism that undermines the possibility of a reticulated convergence/divergence culture, if not the possibility of the movement itself.

Certainly, the constitution of an enemy is not categorically ecological; enmity is largely the product of Carl Schmitt's political theology (Lyotard 1993, 96). Yet, it is curious that just as the potential arises for the articulation of a fundamental shift toward convergence, an environmentalism that feigns principles of participatory action demands the constitution of an enemy (Lyotard 96). Between territory and the demarcation of home, ecologism comes remarkably close to the humanism of war in the name of peace. The home defines a border, barrier, or frontier between first nature and second nature. The home, the empire, or the nation each marks the distinction of blood, territory, and juridical and patriarchal right, over and against an alien, an other, an enemy. In stark contrast with idealizations that suggest either the harmony of nature or the profound altruism of human culture, environmentalism is evoked alongside an intrinsic violence. As Schmitt argued, to maintain an enemy is to maintain the possibility of war. "War follows from enmity. War is the existential negation of the enemy. It is the most extreme consequence of enmity. It does not have to be common, normal, something ideal, or desirable. But it must nevertheless remain a real possibility for as long as the concept of the enemy remains valid" (Schmitt 1932/1996, 33).

Though born under the auspice of convergence, the desire for unity through enmity has created environmentalism through the declaration of cultural war. While I will not go so far as to suggest a simple summation that can bridge the divisions that define the ideological differences currently stifling the development of a contemporary social movement capable of addressing climate change, it does seem, as Jenkins suggests, that any such attempt will require a willingness to step outside ideological barriers and speak across differences in an attempt to deliberate together (2006, 238-239). Whether environmentalism is shallow, deep, post-, or radical, the enemy of environmentalism has been environmentalism itself. Nor, however, do I think this is a fatalistic realization that repeats the end or death of 
environmentalism. If there is to be a convergent/divergent model beyond the negative definition of environmentalism, convergence/divergence can only begin if environmentalism first understands itself as its own undoing.

\section{Works Cited}

Akin, David. "One in two worried about eco-terrorist threats: Poll." Toronto Sun. 20 August 2012. Web. 5 April 2014.

Beck, Ulrich. Risk Society: Towards a New Modernity. Thousand Oaks, CA: SAGE Publications, 1992.

“Canada pulls out of Kyoto.” Environment. CBC Television. 12 December 2011. Video. Web. 10 April 2014.

Carson, Rachel. Silent Spring. Boston: Houghton Mifflin, 1962.

Clements, Frederic E. Plant Succession: An Analysis of the Development of Vegetation. Washington: Carnegie Institution of Washington, 1916.

"Convergence." Dictionary of Ecology. Ed. Michael Allaby. 2nd ed. Oxford: Oxford UP, 1998.

de Sola Pool, Ithiel. Technologies of Freedom: On Free Speech in an Electronic Age. Cambridge, MA: The Belknap Press of Harvard UP, 1983.

"Divergence." Dictionary of Ecology. Ed. Michael Allaby. 2nd ed. Oxford: Oxford UP, 1998.

Environment Canada. "Statement by Minister Kent." 12 December 2011. Web. 5 April 2014.

Evernden, Neil. “The Environmentalists' Dilemma." The Paradox of Environmentalism. Ed. Neil Evernden. Toronto: York University, 1984a. 7-17.

---. Introduction. The Paradox of Environmentalism. Ed. Neil Evernden. Toronto: York University, 1984b. 5-6.

---. The Natural Alien. 1985. Toronto: U of Toronto P, 1995.

Gladwell, Malcolm. "Letter from Saddleback: The Cellular Church, How Rick Warren's Congregation Grew." The New Yorker. 12 September 2005. Web. 10 April 2014.

Jenkins, Henry. Convergence Culture: Where Old and New Media Collide. New York and London: New York UP, 2006.

Klein, Naomi. The Shock Doctrine: The Rise of Disaster Capitalism. Toronto: Knopf Canada, 2007. 
Lyotard, Jean-François. "Oikos." Trans. Bill Readings and Kevin Paul Geiman. Political Writings. Minneapolis: U of Minnesota P, 1993. 96-107.

Naess, Arne. "The Shallow and the Deep, Long-Range Ecology Movement: A Summary." The Deep Ecology Movement: An Introductory Anthology. Ed. Alan Drengson and Yuichi Inoue. Berkeley: North Atlantic Books, 1995. 3-10.

Natural Resources Canada. "An open letter from the Honourable Joe Oliver." 9 January 2012. Web. 5 April 2014.

Nordhaus, Ted, and Michael Shellenberger. "The Death of Environmentalism: Global Warming Politics in a Post-Environmental World." 2004. Web. 5 April 2014.

---. Break Through: Why We Can't Leave Saving the Planet to Environmentalists. 2007. Boston: Mariner Books, 2009.

Pelham, Brett W. "Awareness, Opinions about Global Warming Vary Worldwide." 29 April 2009. Web. 5 April 2014.

Public Safety Canada. "Building Resilience against Terrorism: Canada's CounterTerrorism Strategy.” February 2013. Web. 5 April 2014.

Pugliese, Anita, and Julie Ray. "Awareness of Climate Change and Threat Vary by Region.” 11 December 2009. Web. 5 April 2014.

Schmitt, Carl. The Concept of the Political. 1932. Trans. George Schwab. Chicago: U of Chicago P, 1996.

Stoymenoff, Alexis. "Government labels environmentalists 'terrorist threat' in new report?” Vancouver Observer. 10 February 2012. Web. 5 April 2014.

Vanderheiden, Steve. "Radical Environmentalism in an Age of Antiterrorism." Environmental Politics 17.2 (2008): 299-318. 